\title{
ENSINO DE PATOLOGIA GERAL UTILIZANDO METODOLOGIA ATIVA POR MEIO DE TECNOLOGIAS DE INFORMAÇÃO E COMUNICAÇÃO.
}

ARARAS/SP MAIO/2018

\author{
Thaís Furtado de Camargo - FHO|Uniararas - thaiscamargo@uniararas.br \\ Thiago Antônio Moretti de Andrade - FHO|Uniararas - thiago_andrade@uniararas.br \\ Cintya Aparecida Christofoletti de Figueiredo - FHO|Uniararas - cintyachris@uniararas.br \\ Olavo Raymundo Júnior - FHO|Uniararas - olavo@uniararas.br \\ Marcelo Augusto Marretto Esquisatto - FHO|Uniararas - marcelosquisatto@uniararas.br
}

Tipo: Investigação Científica (IC)

\author{
Natureza: Descrição de Projeto em Andamento \\ Categoria: Métodos e Tecnologias \\ Setor Educacional: EDUCAÇÃO SUPERIOR
}

\begin{abstract}
RESUMO
A formação básica em patologia, tradicionalmente, envolve o uso de livros didáticos, laminário com a casuística e o emprego de microscopia convencional. Nas últimas décadas, o número de recursos baseadas na web se expandiu substancialmente e, com eles, aqueles destinados ao ensinoaprendizagem de Patologia Geral. Recentemente, todas as tecnologias envolvendo imagens e vídeos permitiram levar a tela dos dispositivos móveis, via softwares, inúmeros recursos que permitiram, ou facilitaram, o emprego de metodologias ativas no ensino dessa disciplina. A associação dessas metodologias, em especial o problem based learning (PBL), cria inúmeras oportunidades para 0 treinamento no meio acadêmico e profissional. Os aprendizes serão capazes de entender, manipular e desenvolver habilidades sobre as técnicas histopatológicas, tais como: identificar áreas de relevância diagnóstica e deduzir o acometimento sistêmico a partir da associação de situação de problema e dos recursos colocados à disposição do interessado por meio dos meios digitais. Os alunos não precisarão estar na mesma sala que os recursos e os mestres para aprender. Por fim, várias outras iniciativas de auto-estudo poderão também ser introduzidas para a decisão diagnóstica utilizando recursos virtuais na solução de casos.
\end{abstract}

Palavras-chave: PBL, recursos didáticos, ensino, patologia geral.

\section{AGRADECIMENTOS}

FUNDAÇÃO HERMÍNIO OMETTO PELO SUPORTE 


\section{Introdução}

Os profissionais da saúde têm um importante papel na melhoria das condições de vida da sociedade moderna. É imperativo reconhecer a importância de maximizar sua capacidade de aprendizagem e aquisição de conhecimento (LUCENA; FUCKS, 2000).

A Patologia Geral, definida como o estudo das doenças e alterações que estas provocam em células, tecidos e órgãos, é um dos assuntos mais significativos na área biomédica. Logo, o conhecimento dos processos associados à doença é uma parte essencial da prática profissional, uma vez que tais profissionais precisam estar cientes do impacto da doença na vida das pessoas. Neste contexto, os estudantes universitários necessitam aprender à aplicar os princípios da Patologia Geral na solução de problemas clínicos na prática profissional (LAMPERT, 2002).

Com os recentes avanços em tecnologia e acesso para material eletrônico, os métodos educacionais vêm evoluindo para atender às demandas dos alunos e docentes melhorando os resultados da aprendizagem em áreas básicas e clínicas. No entanto, a eficácia da aprendizagem combinando o uso de metodologias ativas com recursos tecnológicos de comunicação e informação para o ensino de Patologia Geral para estudantes da área de saúde foi pouco investigado (MORAN; MASETTO; BEHRENS, 2000; ALBANESE; MITCHELL, 2003).

Dentre as metodologias ativas mais empregadas no cotidiano universitário, o aprendizado baseado em problemas (do inglês, problem based learning - PBL), prepara o aluno para atuar profissionalmente de forma diferenciada, trazendo para a sala de aula situações representativas de problemas reais que ele vivenciará em sua profissão. $O$ PBL fundamenta-se em um processo de educação continuada como meio de construção de conhecimento que deve ocorrer na forma de aprendizagem autodirigida. Além disso, a aplicação do PBL permite ao discente resgatar conhecimentos prévios de diferentes áreas que foram desenvolvidas em sala de aula, para interpretar uma situação apresentada e assim propor soluções (MEZZARI, 2011).

Dentre os novos recursos tecnológicos mais empregados no estudo da Patologia Geral destaca-se o emprego da digitalização de lâminas histopatológicas para o estudo de casos utilizando coleções virtuais em sistemas baseados na web. Microscopia digital é uma tecnologia que utiliza o computador para apresentação de imagens em alta resolução, o que torna o espécime passível de análise e interpretação via software 
específico (DOWNING,1995; TRIOLA; HOLLOWAY, 2011).

Sendo assim, a combinação de novas metodologias com recursos digitais de ponta oferece para o aluno um ambiente mais flexível, preciso e envolvente, permitindo que o aprendizado ocorra no seu próprio ritmo e de acordo com seu próprio nível de especialização e sem precisar recorrer aos laboratórios de microscopia.

\section{Objetivo}

O presente projeto tem por objetivo o desenvolvimento de uma interface digital para apresentação, discussão e solução de problemas, baseado em metodologia ativa de ensino associado à recursos digitais de imagem e vídeo de Patologia Geral, hospedados em Ambiente virtual de aprendizagem, de forma a promover o aprendizado continuado no conteúdo da disciplina aos alunos do núcleo básico dos cursos de graduação da área da saúde do Centro Universitário Hermínio Ometto - Uniararas.

\section{Procedimentos metodológicos}

\section{Elaboração dos recursos digitais}

As lâminas histopatológicas a serem utilizadas na elaboração do repositório digital encontram-se no acervo didático do Laboratório de Biologia Estrutural do Centro Universitário Hermínio Ometto (FHO|UNIARARAS).

A escolha dos espécimes e o roteiro para identificação das estruturas fundamentais da lesão, a serem discutidas no problema serão preparados segundo a prática utilizada pelos docentes para orientação dos alunos na disciplina em sala de aula e laboratório didático. A estrutura básica do recurso consistirá em um menu inicial, proposto na forma de uma imagem principal e/ou outras acessórias que irão subsidiar a compreensão do caso-problema. Em cada imagem será apontada uma área relacionada aos elementos principais para a compreensão das estruturas macro e microscópicas relacionadas. 
Assim, o aluno poderá compreender as estruturas microscópicas e relacioná-las aos órgãos acometidos do paciente. Cada caso consistirá em uma rápida apresentação do problema, seguido pelo apontamento das estruturas acometidas e o descritivo macroscópico das alterações. Por fim, a maior parte dos conteúdos focará a apresentação e descrição das alterações teciduais da situação problema, sempre associado à imagens de órgãos e tecidos acometidos. A instituição já possui no acervo todas as lâminas digitalizadas em alta resolução que subsidiarão o projeto. Estas foram obtidas a partir dos trabalhos realizados pelo Núcleo de Tecnologias Digitais em Patologia Geral (NTDP), da UNESP em Botucatu/SP, pelo equipamento 3DHistech Pannoramic MIDI (3D HISTECH Ltda., Budaspeste, Hungria), e que podem ser observadas pelo software Pannoramic Viewer 1.15 (3D HISTECH Ltda., Budaspeste, Hungria).

Cada caso, com todas as suas etapas ou parte delas, poderá fazer uso de vídeos didáticos gravados pelo docente responsável e, revisado por outro especialista da equipe, de até 5 minutos. Os vídeos serão narrados em off, ao passo que as imagens serão mostradas e as estruturas apontadas simultaneamente. A gravação será obtida pela captura da tela do computador, por meio do Software Jing (TechSmith Corporation, Michigan, E.U.A.), editado e finalizado pelos profissionais do Centro de Tecnologia CETEC/ FHO|Uniararas. Os conteúdos capturados serão editados e finalizados em software Adobe Premiere Pro 2.0 (Adobe Systems, San José, E.U.A.). Após a aprovação do vídeo pelos responsáveis da disciplina, os mesmos comporão os recursos didáticos associados a cada caso e estarão depositados no Ambiente Virtual de Aprendizagem - AVA/Moodle (Moodle Pty Ltda, Perth, Australia).

O uso do AVA/Moodle permitirá o acesso irrestrito a todos os casos-problema, com total liberdade de escolha de acesso aos conteúdos a serem consultados e/ou estudados. A organização de cada caso respeitará um protocolo que será adotado uniformemente em todos os incluídos na proposta.

\section{Elaboração da interface para o aprendizado baseado em problemas}

$\mathrm{Na}$ abertura de cada caso, o aluno terá acesso via AVA/Moodle a informações sobre o problema: sua apresentação e os objetivos a serem alcançados. O aluno será, primeiramente, estimulado a fazer uma revisão dos principais tópicos que o subsidiarão para a interpretação do problema e a respectiva proposição da solução. Os tópicos estarão organizados em links para acesso aos conteúdos via Internet. Estes serão 
organizados pelos professores da disciplina. $\mathrm{O}$ acesso aos conteúdos será organizado de acordo com os problemas propostos. A comunicação entre os alunos e docentes será estabelecida por meio de fóruns e e-mails disponibilizados pelo Suporte AVA. Além do corpo pedagógico da disciplina, uma equipe de apoio dará suporte à estrutura tecnológica. A organização dos conteúdos e a apresentação dos problemas, após serem elaborados pelos responsáveis, passarão por uma formatação gráfica e estética realizada pelos webdesigners da Instituição. A adaptação dos conteúdos para postagem no Ambiente de Aprendizagem será realizada pelos programadores do Desenvolvimento EaD. O cadastramento, organização dos grupos e liberação dos casos/conteúdos de apoio pelo sistema serão de responsabilidade da equipe de TI.

\section{Primeiros casos-problema propostos}

Os primeiros casos-problema que serão trabalhados com os alunos utilizando a metodologia e os recursos descritos nesta proposta estarão finalizados no $1^{\circ}$ semestre de 2019.

A lista de propostas está relatada abaixo:

1. Termos básicos utilizados na Patologia Geral;

2. Morte celular: necrose e apoptose;

3. Inflamação, cicatrização e regeneração teciduais;

4. Disfunções hemodinâmicas;

5. Neoplasias.

Com o objetivo de facilitar a compreensão e aumentar a adesão dos estudantes ao projeto, os casos obedecerão a uma hierarquização no grau de dificuldade na solução dos problemas propostos. 
Inicialmente, o projeto será implantado para os alunos de graduação do 5ํㅜ período dos cursos da área da saúde da Instituição, em 2019. Eles receberão em sala um convite para acessarem e participarem da proposta com a orientação de atividade complementar. Ao término do semestre, os alunos serão convidados a responder a uma pesquisa digital de autoavaliação e avaliação do projeto. Os questionários avaliarão a opinião dos participantes, quanto aos conteúdos, estímulo para o aprendizado propiciado pela metodologia baseada em problemas e os recursos didáticos e tecnológicos empregados, além dos aspectos de usabilidade e navegabilidade. As informações obtidas serão compiladas em tabelas e gráficos e apresentados em futuros eventos da área de educação superior.

\section{Considerações Finais}

Diante de um mercado de trabalho cada vez mais competitivo, a formação superior de qualidade deve impulsionar as mudanças na sociedade. Porém, diante do aumento no acesso de estudantes trabalhadores ao ensino superior, a proposição de novas metodologias, que colocam o aluno como protagonista do ensino, associado a recursos digitais, organizados de forma a ampliar o acesso e facilitar a discussão de ideias e o aprofundamento no aprendizado, terá um enorme potencial na motivação dos alunos a se capacitarem e estes se sentirem estimulados a romper os paradigmas da educação superior. Além disso, a associação da metodologia ativa/recursos digitais de pronto propiciará ao estudante o desenvolvimento de habilidades e posturas frente a diversas situações que farão parte da rotina do profissional, que o diferenciará no mercado de trabalho.

\section{Referências Bibliográficas}

ALBANESE, M.A.; MITCHELL, S. Problem-based learning: a review of literature on its outcomes and implementation issues. Academic Medicine. v. 68, n. 1, p. 52-81, 2003. 
DOWNING, S.W. A multimedia-based histology laboratory course: elimination of the traditional microscope laboratory. Medinfo, v. 8, n. 2, p. 1695-1696, 1995.

LAMPERT, J.B. Tendências de mudança na formação médica. São Paulo: Hucitec, 2002.

LUCENA, C.; FUCKS, H. A educação na era da Internet. Rio de Janeiro: Clube do Futuro, 2000.

MEZZARI, A. O Uso da Aprendizagem Baseada em Problemas (ABP) como Reforço ao Ensino Presencial Utilizando o Ambiente de Aprendizagem Moodle. Revista Brasileira de Educação Médica. v. 35, n. 1, p. 114-121, 2011.

MARC M TRIOLA, M.M.; HOLLOWAY, W. J. Enhanced virtual microscopy for collaborative education. BMC Medical Education. v. 11, n. 4, 2011.

MORAN, J. M.; MASETTO, M. T.; BEHRENS, M. A. Novas tecnologias e mediação pedagógica. 12ª edição. São Paulo: Editora Papirus, 2000. 176p. 